\title{
Osteoinductivity of HAp Films with Different Surface Morphologies Coated by the Thermal Substrate Method in Aqueous Solutions
}

\author{
Kensuke Kuroda, Shinji Nakamoto*, Yoshihiro Miyashita*, Ryoichi Ichino and Masazumi Okido \\ Department of Materials Science \& Engineering, Graduate School of Engineering, Nagoya University, Nagoya 464-8603, Japan
}

The aim of this study was to investigate the in vivo performance of implants coated with hydroxyapatite (HAp) with different surface morphologies. HAp coatings were formed on commercially pure titanium rods ( $2 \mathrm{~mm}$ in diameter, $5 \mathrm{~mm}$ in length) by the thermal substrate method in an aqueous solution that included $\mathrm{Ca}\left(\mathrm{H}_{2} \mathrm{PO}_{4}\right)_{2}$ and $\mathrm{CaCl}_{2}$. The coating experiments were conducted at $40-140^{\circ} \mathrm{C}$ and $\mathrm{pH}=8$ for 15 or $30 \mathrm{~min}$. All the specimens were covered with HAp, which had different morphologies such as net-like, plate-like, and needle-like. The coated rods were implanted in the tibiae of 10-week-old male rats. Noncoated titanium rods were used as the control in this study. The constructs were retrieved 14, 28, and 56 days postimplantation and examined for new bone formation and tissue response in the cancellous and cortical bone, respectively. After 14 days implantation, new bone formed on both the HAp-coated and noncoated titanium rods in the cancellous and cortical bone. However, the bone-implant contact ratio, which was used for the evaluation of new bone formation, was significantly dependent on the surface morphology of the HAp, and the results demonstrated that the needle-like coating appears to promote rapid bone formation. [doi:10.2320/matertrans.47.1391]

(Received February 1, 2006; Accepted March 2, 2006; Published May 15, 2006)

Keywords: hydroxyapatite coating, surface morphology, needle-like hydroxyapatite, thermal substrate method, in vivo

\section{Introduction}

Calcium phosphates, specifically hydroxyapatite $\left(\mathrm{Ca}_{10}\left(\mathrm{PO}_{4}\right)_{6}(\mathrm{OH})_{2}, \mathrm{HAp}\right)$, are of interest in bone-interfacing implant applications because of their demonstrated osteoconductive properties. ${ }^{1)}$ Hydroxyapatite is considered to be a bioactive material, and is used in the fabrication of medical and dental implants, usually in the form of a coating on a metallic substrate to compensate for its poor intrinsic mechanical properties. Many methods of forming HAp and other calcium phosphate coatings on metallic substrates have been reported. We have proposed a new hydro-coating method for calcium phosphate, a thermal substrate method that overcomes several weak points in the traditional hydroprocesses. ${ }^{2)}$ In other papers on hydroprocessing, ${ }^{3-10)}$ several factors in the solution affecting the HAp coating have been extensively examined, such as the solute concentration, the $\mathrm{pH}$, the type of ion, its concentration, and additives. We have already reported that HAp coating of substrates by the thermal substrate method is experimentally feasible, and confirmed experimentally that the ion source, the $\mathrm{Ca} / \mathrm{P}$ molar ratio in the solution, and the surface roughness and topography of the substrate affected the precipitate..$^{2,11-13)}$ In addition, the use of the thermal substrate method with different coating conditions in aqueous solutions initiated HAp coverings with different surface morphologies. ${ }^{14)}$ The pyrocoating process, the plasma spray method, ${ }^{15)}$ is widely applied to HAp coating, and the in vivo osteoinduction properties of crystal HAp, amorphous HAp, and composite HAp have been assessed. However, the influence of the shape or surface morphology of the coated HAp crystal on osteoinduction is not yet clear. In this study, HAp coatings with different surface morphologies were formed on Ti rods by the thermal substrate method, and samples were implanted in rat tibiae for up to 56 days to evaluate the extent of new bone formation.

*Graduate Student, Graduate School of Engineering, Nagoya University

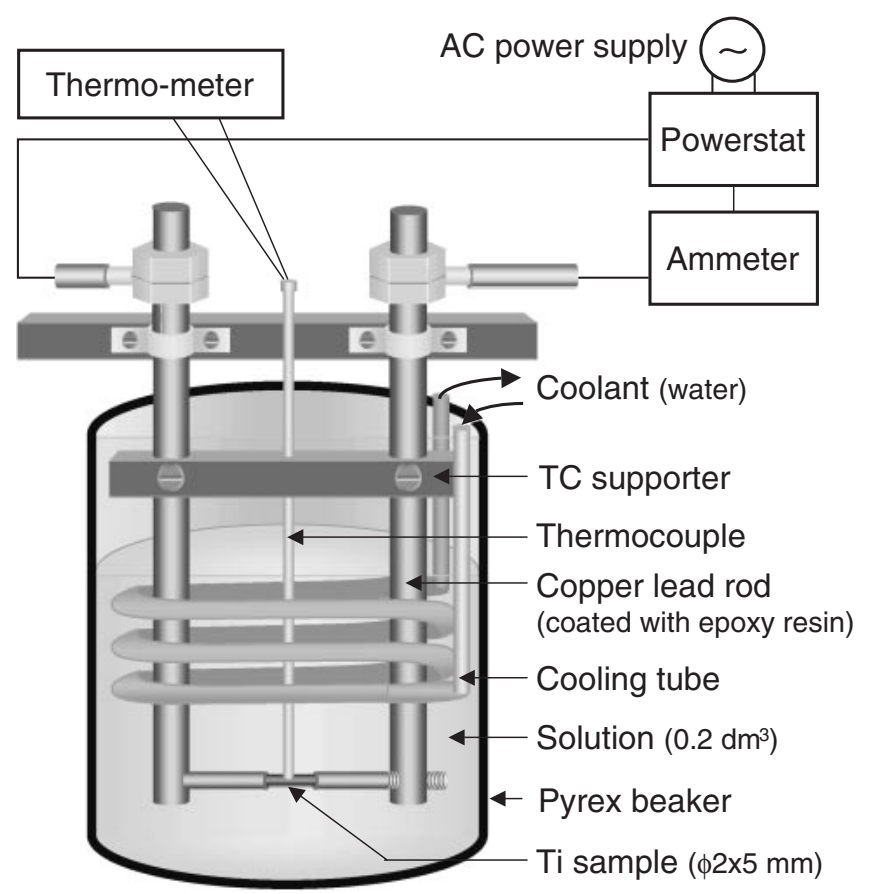

Fig. 1 Experimental apparatus for the HAp coating.

\section{Materials and Methods}

\subsection{HAp coating}

Figure 1 shows the experimental apparatus used to produce the HAp coatings. ${ }^{2}$ The aqueous solution consisted of $0.3 \mathrm{mmol} \mathrm{dm}^{-3} \mathrm{Ca}\left(\mathrm{H}_{2} \mathrm{PO}_{4}\right)_{2}$ and $0.7 \mathrm{mmol} \mathrm{dm}^{-3} \mathrm{CaCl}_{2}$. The $\mathrm{pH}$ of the solution was adjusted to 8 by the addition of aqueous $\mathrm{NaOH} .{ }^{11,12)}$ Commercially pure titanium rods $(\phi 2 \times$ $5 \mathrm{~mm}$ ) were polished with $\mathrm{SiC}$ emery paper (\#400 grid) before the coating experiment. The specimens, sandwiched between copper electrodes, were immersed in $0.2 \mathrm{dm}^{3}$ of aqueous solution and shaken, in order to release any air 
bubbles that may have adhered to their surfaces. An alternating current (up to 50 A) was passed through the samples via the copper electrodes, heating the samples. The temperature of the specimen was measured by a calibrated thermocouple, which was in contact with the surface of the specimens. The temperature was maintained at $40-140^{\circ} \mathrm{C}$ for 15 or $30 \mathrm{~min}$ by the current amplitude, and the coating process was terminated by switching off the power. During the coating, the solution was water cooled to prevent precipitation of HAp in the solution, caused by increases in the temperature of the solution; the solution temperature was kept at $15^{\circ} \mathrm{C}$. In the case of low temperature experiments, at less than $60^{\circ} \mathrm{C}$, HAp did not precipitate easily on the substrate when using the above solution. Therefore, ethanol $\left(1 \mathrm{~mol} \mathrm{dm}^{-3}\right)$ was added to the solution, ${ }^{16)}$ and during Joule heating, ultrasonic waves $(100 \mathrm{~Hz})$ were applied to the sample using the ultrasonic cleaning equipment. ${ }^{17)}$ The properties of the coated samples were studied using X-ray diffraction (XRD), energy dispersive X-ray analysis (EDX), Fourier transform infrared spectroscopy (FT-IR), and scanning electron microscopy (SEM).

\subsection{In vivo study}

Following the above treatment to produce the coating, samples were implanted in the tibial metaphysis of rats, and the bioactivities of the coatings were evaluated from new bone formation and tissue response. Before surgery, all implants were cleaned ultrasonically in distilled water sterilized in a steam autoclave $\left(121^{\circ} \mathrm{C}, 20 \mathrm{~min}\right)$, and immersed in a chlorhexidine gluconate solution (HIBITEN). For the experimental procedure, 340-400 g 10-week-old male Sprague Dawley rats (Charles River Japan, Inc.) were used. The animals were kept in quarantine for 7 days. Prior to surgery, the rats were anesthetized using the pentobarbital (25-30 $\mathrm{mg} \mathrm{kg}^{-1}$ ) and the incision sites (right and left) and surrounding area were shaved and cleaned with povidine iodine solution and $70 \%$ ethanol. Slightly oversized holes, which did not pass completely through the bone, were created with a low speed rotary drill under profuse saline irrigation, and the bone debris was washed away with saline. Subsequently, implants were inserted in these holes, and Penicillin $\mathrm{G}$ was administered for the prevention of infection. The subcutaneous tissue and skin were then closed and sterilized with povidine iodine solution.

After surgery, rats were housed individually in polycarbonate cages, and monitored daily for any complications or ill effects. Rats were sacrificed after 14, 28 or 56 days, and the implants with their surrounding tissue were retrieved. The specimens were fixed in $10 \%$ neutral buffered formalin solution, rinsed in distilled water, dehydrated in a graded series of ethanols, and embedded in methylmethacrylate. Following polymerization, each implant block was sectioned to $20 \mu \mathrm{m}$ thick slices using microcutting machine and microgrinding machine. The final sections were stained with toluidine blue.

Bone-implant contact was determined by linear measurement of direct bone contact with the implant surface. The sum of the length of the bone formation on the implant surface was measured and expressed as a percentage of the total implant length (bone-implant contact ratio) in the cancellous bone and the cortical bone. Differences in boneimplant contact ratio between the HAp-coated implants and noncoated implants were statistically analyzed by the TukeyKramer method. Differences were considered statistically significant at $p<0.05$.

\section{Results and Discussion}

\subsection{HAp coating}

Typical SEM photographs and XRD patterns for the surface of the specimens are shown in Figs. 2(a)-(c) and 3, coated at $40-140^{\circ} \mathrm{C}$ for 15 or $30 \mathrm{~min}$. All the specimens were covered with a white precipitate, identified as predominantly HAp, and which included a very small amount of $\mathrm{CO}_{3}{ }^{2-}$ (FTIR) and whose $\mathrm{Ca} / \mathrm{P}$ ratio was $1.49-1.52$ (EDX). The surface morphology of the precipitate strongly depended on coating temperature; the low temperature coating $\left(40^{\circ} \mathrm{C}\right)$ gave netlike HAp (a), high temperature $\left(140^{\circ} \mathrm{C}\right)$ needle-like (c), and mid temperature $\left(60^{\circ} \mathrm{C}\right)$ plate-like HAp (b). The tendency for the crystallinity of HAp to change depending on the temperature agrees with the previous report by Ban and Maruno. ${ }^{4)}$ However, we could not find a relationship between the surface morphology and the crystal orientation. Moreover, the brittleness of the coated layer prevented measurement of the surface roughness of the coated samples. From the cross-sectional view of the sample coated at $140^{\circ} \mathrm{C}$ for $15 \mathrm{~min}$, the thickness of the film was less than $2-3 \mu \mathrm{m}$. However, we could not examine the mass and the thickness changes of the precipitate with coating temperature because of the small amount of precipitate.

Before in vivo testing, all the specimens had to be sterilized in a steam autoclave $\left(121^{\circ} \mathrm{C}, 20 \mathrm{~min}\right)$, which was higher than the temperature in the low temperature coating (40 and $60^{\circ} \mathrm{C}$ ). Therefore, we were afraid that the surface morphology of the coated filmwould be changed. Direct exposure to the high temperature steam in the sterilizer caused no change in the surface morphologies (Figs. 2(d)-(f)). A comparison by XRD, FT-IR, and EDX analysis of the components in the film before and after autoclaving showed no significant differences. Therefore, after cleaning and sterilization, the coated specimens with the three different morphologies were subjected to in vivo testing.

\subsection{In vivo study}

Figure 4 shows a typical optical microscope image of a cancellous bone-implant interface for an HAp-coated implant (needle-like) at 14 days after implantation. The thin HAp film could not been seen in the image. Fibrocyte were observed on the Ti implant in places, but much new bone had formed on the implant, even after only 14 days.

The results of histomorphometicy measurements of boneimplant interfaces up to 56 days are presented in Fig. 5, and compared with the control implants (non-coated Ti). In the region of the cancellous bone, which has much body fluid circulation, the bone-implant contact ratio was relatively higher than in the cortical bone regions. The influence of the different surface morphologies on the bone-implant contact ratios is apparent. In particular, in the cancellous bone after 14 days implantation, the bone-implant contact ratio is the highest in the sample coated with the needle-like HAp. There 

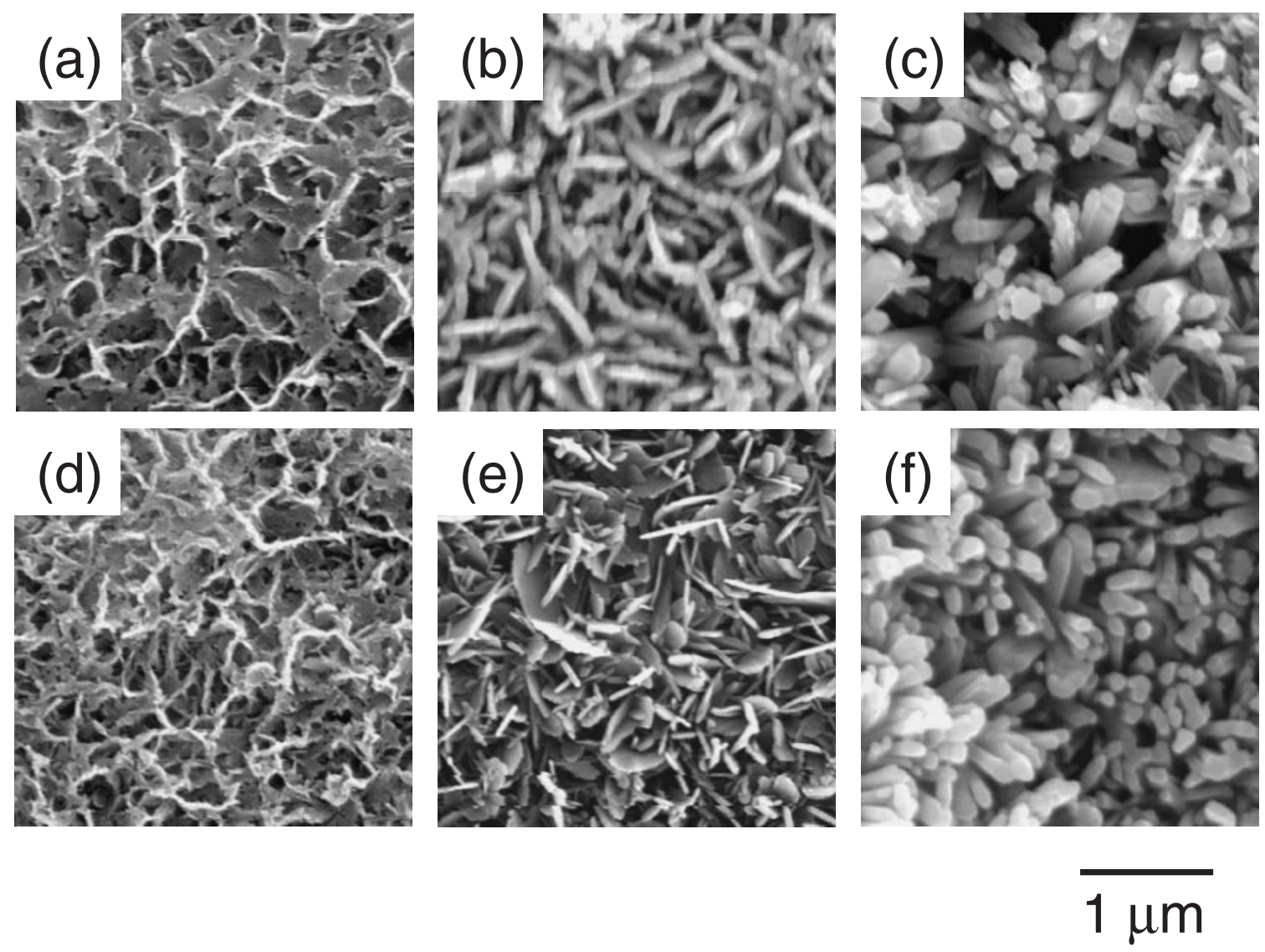

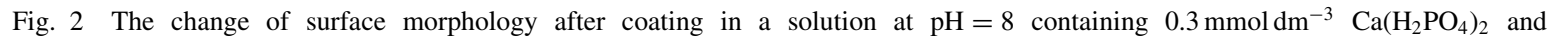
$0.7 \mathrm{mmol} \mathrm{dm}^{-3} \mathrm{CaCl}_{2}$. (a) $40^{\circ} \mathrm{C}, 30 \mathrm{~min}$, ultrasonic waves $(100 \mathrm{~Hz})$, ethanol added $\left(1 \mathrm{~mol} \mathrm{dm}^{-3}\right)$ (b) $60^{\circ} \mathrm{C}, 30 \mathrm{~min}$, ultrasonic waves $(100 \mathrm{~Hz})$, ethanol added $\left(1 \mathrm{~mol} \mathrm{dm}^{-3}\right)$ (c) $140^{\circ} \mathrm{C}, 15 \mathrm{~min}$, no additions (d) $40^{\circ} \mathrm{C}, 30 \mathrm{~min}$, ultrasonic waves $(100 \mathrm{~Hz})$, ethanol added $\left(1 \mathrm{~mol} \mathrm{dm}^{-3}\right)(\mathrm{e}) 60^{\circ} \mathrm{C}, 30 \mathrm{~min}$, ultrasonic waves $(100 \mathrm{~Hz})$, ethanol added $\left(1 \mathrm{~mol} \mathrm{dm}^{-3}\right)(\mathrm{f}) 140^{\circ} \mathrm{C}, 15 \mathrm{~min}$, no additions (a)(b)(c): ascoated, (d)(e)(f): after sterilization in a steam autoclave.

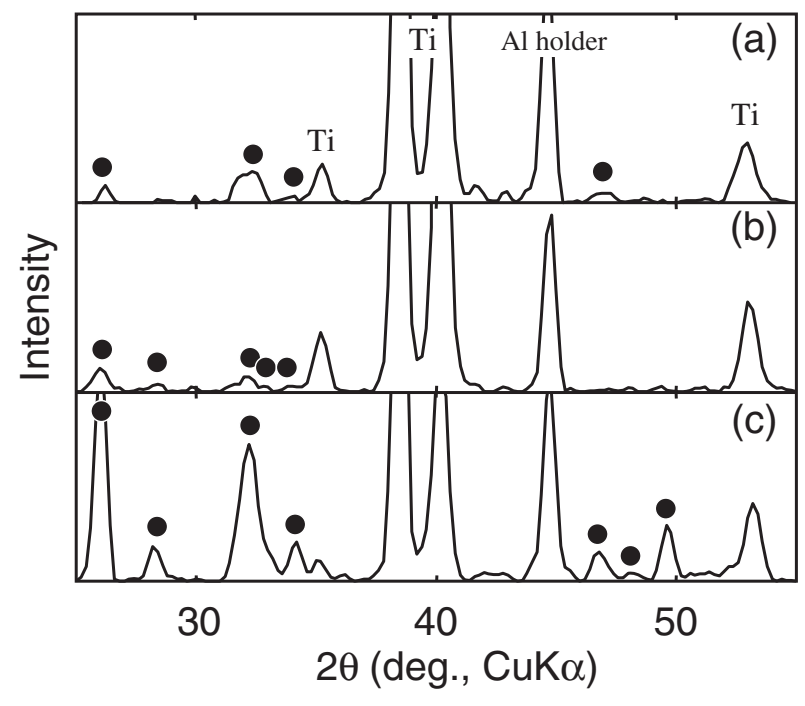

Fig. 3 XRD patterns after coating in a solution at $\mathrm{pH}=8$ containing $0.3 \mathrm{mmol} \mathrm{dm}^{-3} \mathrm{Ca}\left(\mathrm{H}_{2} \mathrm{PO}_{4}\right)_{2}$ and $0.7 \mathrm{mmol} \mathrm{dm}^{-3} \mathrm{CaCl}_{2}$. •: $\mathrm{HAp}$ (a) $40^{\circ} \mathrm{C}, 30 \mathrm{~min}$, ultrasonic waves $(100 \mathrm{~Hz})$, ethanol added $\left(1 \mathrm{~mol} \mathrm{dm}^{-3}\right)$ (b) $60^{\circ} \mathrm{C}, 30 \mathrm{~min}$, ultrasonic waves $(100 \mathrm{~Hz})$, ethanol added $\left(1 \mathrm{~mol} \mathrm{dm}^{-3}\right)$ (c) $140^{\circ} \mathrm{C}, 15 \mathrm{~min}$, no additions.

was a similar tendency in the cortical bone. In the cortical bone up to 56 days postimplantation, with the exception of the needle-like HAp, which had a high bone-implant contact

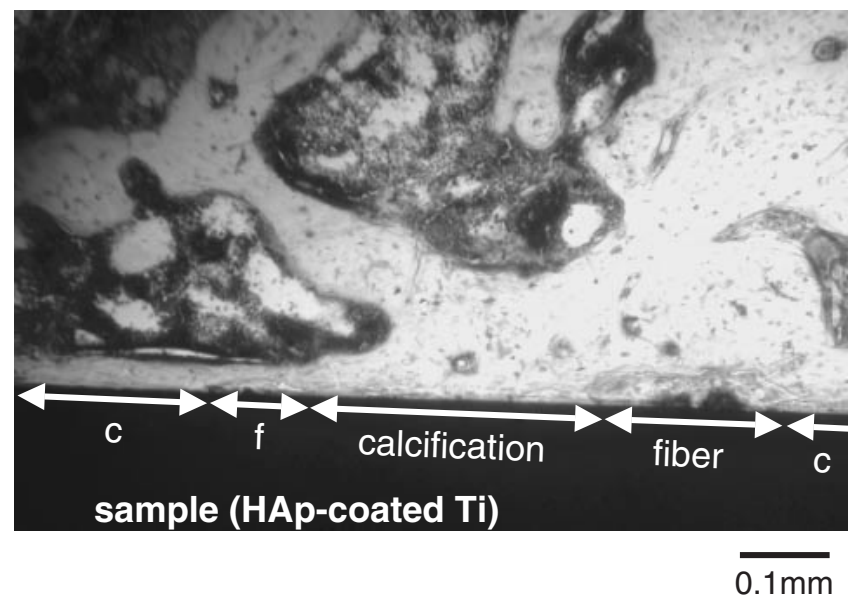

Fig. 4 Light microscopy of bone-implant interface of HAp coated implant (needle-like) at 14 days after implantation in cancellous bone.

ratio from an early stage, the bone-implant contact ratio increases little by little and the ratio is higher than that for the noncoated $\mathrm{Ti}$. In the cancellous bone, in contrast, there is no apparent difference in the bone-implant contact ratios between the samples coated with net-like and plate-like HAp and the noncoated Ti sample. The bone-implant contact ratio in the cancellous bone approached $30 \%$ after 56 days 


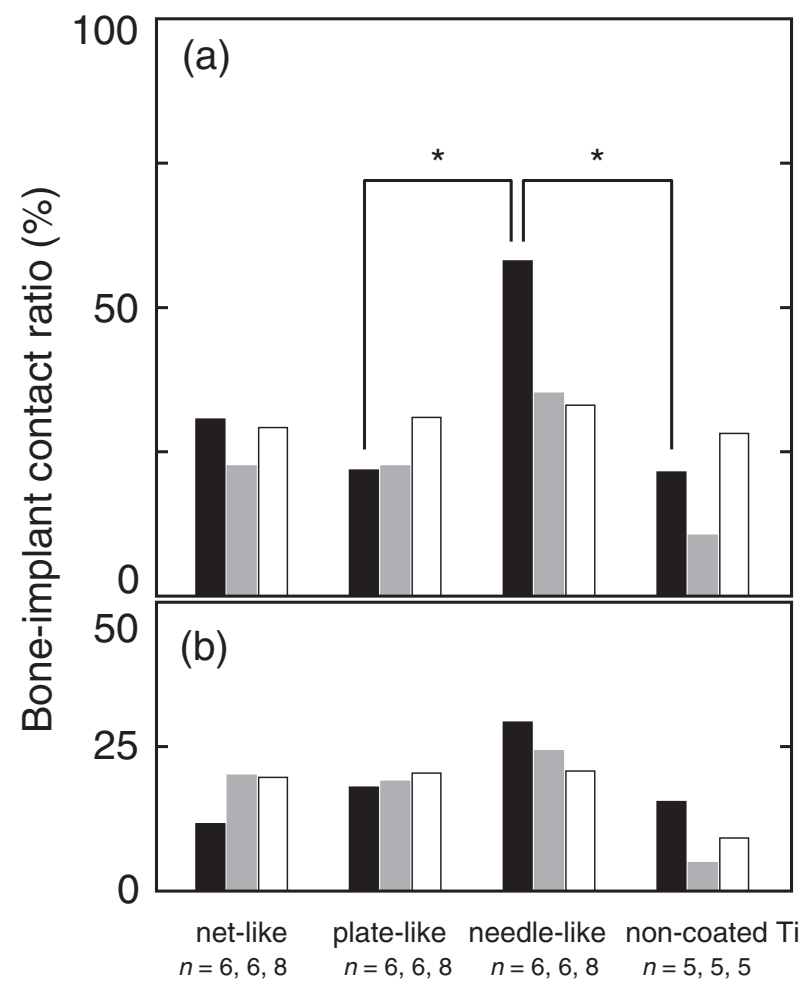

Fig. 5 Histomorphometric results showing the percentage of bone formed on the HAp coated implants with various surface morphologies. (a) cancellous bone, (b) cortical bone. $\square$ : 14 days, $\square: 28$ days, $\square$ : 56 days. ${ }^{*} p<0.05$.

implantation, regardless of the presence of the HAp coating and the surface morphology of the coated HAp. This value agrees well with the percentage of hard tissue in healthy cancellous bone in rats. Therefore, in cancellous bone, the samples coated with the needle-like HAp give the high boneimplant contact ratios in the early implantation stage. Then, with longer-term implantation, it is thought that the HAp coating gradually loses its effect on osteoinduction, and there is no difference between the HAp coated and noncoated samples after 56 days implantation. We could not established whether this behavior resulted from the peeling away of the coated film or HAp resorption by osteoclasts or macrophages. Nonetheless, it bears mentioning that the needle-like HAp has a higher osteoinductivity than the net- and plate-like HAps in the early implantation stage.

\section{Conclusions}

(1) All the Ti specimens were coated with HAp by using the thermal substrate method in the aqueous solution, which gave HAps with different morphologies. The surface morphology strongly depended on coating temperature: the low temperature coating $\left(40^{\circ} \mathrm{C}\right)$ initiated net-like HAp, high temperature $\left(140^{\circ} \mathrm{C}\right)$ needle-like, and middle temperature $\left(60^{\circ} \mathrm{C}\right)$ plate-like HAp.

(2) The samples coated with the needle-like HAp had high osteoinductivity in the cancellous bone in the early implantation stage (in vivo study).

\section{Acknowledgement}

This work was partially supported by a Grant-in-Aid for Young Scientist (B) (No. 15760520) (No. 17760564) from the Japan Society for the Promotion of Science (JSPS) and the Nippon Sheet Glass Foundation for Materials Science and Engineering.

\section{REFERENCES}

1) L. L. Hench and J. Wilson: An Introduction to Bioceramics. (World Scientific, Singapore, 1993).

2) K. Kuroda, R. Ichino, M. Okido and M. O. Takai: J. Biomed. Mater. Res. 59 (2002) 390-397.

3) H. Monma: J. Mater. Sci. 29 (1994) 949-953.

4) S. Ban and S. Maruno: J. Biomed. Mater. Res. 42 (1998) 387-395.

5) Y. Han, K. Xu and J. Lu: J. Mater. Sci. Mater. Med. 10 (1999) 243-248.

6) M. Okido, K. Kuroda, M. Ishikawa, R. Ichino and O. Takai: Solid State Ionics 151 (2002) 42-57

7) M. Shirkhanzadeh: J. Mater. Sci. Mater. Med. 6 (1995) 90-93.

8) I. Zhitomirsky and L. Gal-or: J. Mater. Sci. Mater. Med. 8 (1997) 213219.

9) Y. Li, L. DeGroot, J. Dewijn, C. P. A. T. Klein and S. V. D. Meer: J. Mater. Sci. Mater. Med. 5 (1994) 326-331.

10) T. Iizuka and A. Nozuma: J. Ceram. Soc. Jpn. 106 (1998) 820-823.

11) K. Kuroda, R. Ichino, M. Okido and O. Takai: J. Biomed. Mater. Res. 61 (2002) 354-359.

12) K. Kuroda, Y. Miyashita, R. Ichino, M. Okido and O. Takai: Mater. Trans. 43 (2002) 3015-3019.

13) K. Kuroda, S. Nakamoto, R. Ichino, M. Okido and R. M. Pilliar: Mater. Trans. 46 (2005) 1633-1635.

14) K. Kuroda, Y. Miyashita, R. Ichino and M. Okido: Mater. Sci. Forum 426-432 (2003) 3189-3194.

15) S. W. K. Kweh, K. A. Khor and P. Cheang: Biomater. 21 (2000) 12231234

16) M. S. Tung and T. J. O’Farrell: Coll. Surf. A 110 (1996) 191-198.

17) Y. Fang, D. K. Agarwal, D. M. Roy, R. Roy and P. W. Brown: J. Mater. Res. 7 (1992) 2294-2298. 